\title{
Governance choice on a serial network
}

\author{
Feng Xie · David Levinson
}

Received: 24 August 2008 / Accepted: 21 April 2009 / Published online: 7 May 2009

(C) Springer Science+Business Media, LLC 2009

\begin{abstract}
This paper analyzes governance choice in a two-level federation in providing road infrastructure across jurisdictions. Two models are proposed to predict the choice of centralized or decentralized spending structure on a serial road network shared by two districts. While the first model considers simple Pigouvian behavior of governments, the second explicitly models political forces at both a local and central level. Both models led to the conclusions that the spending structure is chosen based on a satisfactory comprise between benefits and costs associated with alternative decision-making processes, and that governance choice may spontaneously shift as the infrastructure improves temporally.
\end{abstract}

Keywords Governance choice $\cdot$ Transportation · Infrastructure $\cdot$ Fiscal federalism

\section{Introduction}

It has long been observed that the development of transportation systems has been characterized by "a constantly shifting mix of private enterprise, on the one hand, and government initiatives at local, state, and national levels, on the other hand" (Taaffe et al. 1996). The shift between alternative ownership structures and regulatory regimes has profoundly influenced the provision of transportation infrastructure, both in the policy-making process, basic financing, and in the shaping of specific routes and network patterns. ${ }^{1}$

\footnotetext{
${ }^{1}$ Transportation economists have long been investigating the issues of transportation financing under alternative pricing and regulatory regimes. Quantitatively, they have approached the issue from both a theoretical and empirical perspective. Theoretical exploration primarily focuses on the endogenous choices of prices, investment, and ownership in classic small networks with one Origin-Destination pair and two or more
}

\section{F. Xie $(\bowtie)$}

2350 Glenmont Circle \#2350 1/2, Silver Spring, MD 20902, USA

e-mail: xiex0055@umn.edu

D. Levinson

University of Minnesota, 500 Pillsbury Drive SE, Minneapolis, MN 55455, USA

e-mail: dlevinson@umn.edu 


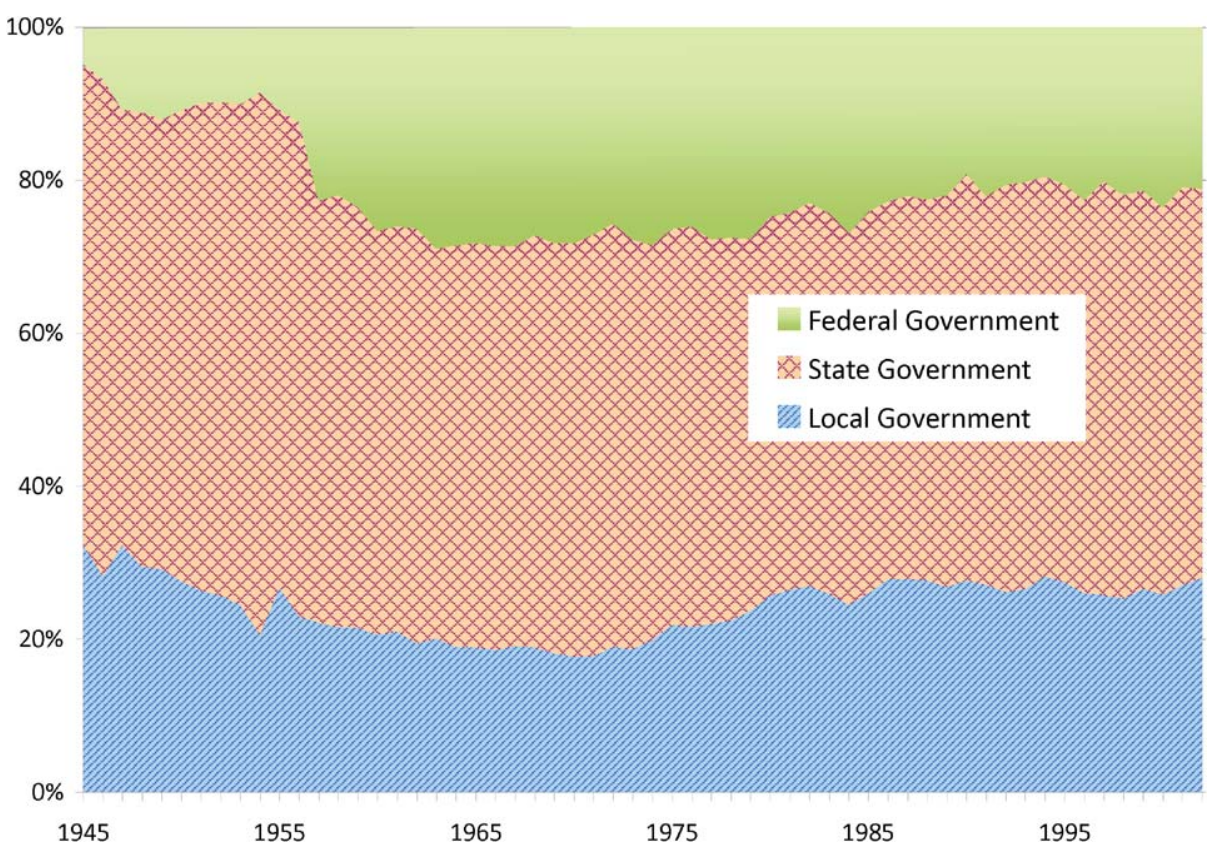

Fig. 1 Total receipts from gasoline and other road taxes for highways by different government levels during 1945-2002. (Data Source: Federal Highway Administration 2005)

Narrowing our focus to the government provision of transportation infrastructure, ${ }^{2}$ although the roles of governments at different levels have always been intertwined in reality, some centralizing tendency to move from local to state to federal levels has been noted when the major modes of waterways, railways, turnpikes, and roads were deployed in the United States (Taylor 2004; Garrison and Levinson 2005; Bogart 2005). For instance, most US turnpikes were local throughout the nineteenth century, initially organized by larger cities connecting ports to hinterlands.

As transportation systems developed, however, the roles of the state and federal government became more and more prominent. Railway consolidation and regulation, as well as a revival of inland waterways and certain canals, would not have been possible without government involvement and financial aid at the state and federal levels. While the promotion of road transportation had been primarily at local and state levels during the early twentieth century, the federal government acquired the major promotional role during the interstate highway era post-1956. Evidence is available in Fig. 1, which displays the percentage of total receipts from gasoline and other road taxes for highways by government levels during 1945-2002. Over this period, 1956 witnessed a salient increase in the federal share of

alternative routes (Button 1998; de Palma and Lindsey 2000; Verhoef et al. 1996; Verhoef and Rouwendal 2004; Borger et al. 2005; Zhang and Levinson 2007) or with stylized network geometries (Levinson 2002). Empirical studies in large part explore the relationship between the performance of transportation systems, the allocation of funds or decision-making power across regulatory hierarchies, and economic and demographic characteristics of jurisdictions based on cross-jurisdiction statistical analyses (Humplick and Moini-Araghi 1996; Levinson and Yerra 2002)

${ }^{2}$ In most countries, transportation is mostly publicly funded. 
highway receipts, immediately following the establishment of the Federal Highway Trust Fund (HTF) to finance the construction of the Interstate highway system (McDaniel and Coley 2004). As infrastructure has aged and congestion grown after the completion of the Interstate system, the call for better coordination between jurisdictions and departments involved in the management, operations, and expansion of regional road systems has been growing in intensity. In response to the interconnected and interdependent nature of current road systems, the establishment of Metropolitan Planning Organizations (MPO) and various Regional Operating Organizations (ROOs) in recent years has marked a shift of institutional structure of transportation decision making from a local to a regional level (Haynes et al. 2005).

While decision making at a higher government level in a multi-jurisdictional road system seems to be desirable in terms of better coordination across jurisdictions, it also brings institutional and political problems that may lead to inequity or economic inefficiency. Taking the US Federal-Aid Highway Program as an example, policy debate has lasted over the past 20 years regarding the distribution of federal highway funding. The controversy arose as the program's payment to the individual states did not match the amount of federal highway taxes each state's highway users pay to the Highway Trust Fund, which is commonly referred to as the "donor-donee" problem (Kirk 2004). Donee states like Alaska have experienced high returns from the HTF, donor states like California have always contributed more than they have received, while some states like Ohio have experienced instability and cycling in terms of their donor/donee status. ${ }^{3}$ In general, the allocation of federal highway funds is based on formulas that are biased in favor of states with relatively low highway use to maintain national integration (Johnson and Libecap 2000). In such an allocatively imbalanced program, a fiscal correspondence problem arises when policy makers in donee states spend to benefit their constituent travelers and suppliers, but whose welfare costs are borne by taxpayers in all the states. Regional transportation institutions have their misallocation problems too. As Haynes et al. (2005) pointed out, MPOs usually adopt the "one government/one vote" decision structure regardless of the heterogeneous distribution of regional population and transportation demand, which tends to under-represent central cities and poorer populations, and over-represent suburbs and higher income groups. The legislative process at the federal level causes additional problems. Politicians form coalitions to maintain political support and reach policy agreements in Congress, at the obvious cost of the economic efficiency of their policy decisions. ${ }^{4}$

The purpose of this study, with a particular focus on the public provision of road infrastructure, is to examine how transportation policy decisions have been instituted by the government at various levels, and which level of government would be preferable to deliver infrastructure projects at a particular stage of transportation development. From an evolutionary perspective, the study also explores why the institutional structure of policy making has spontaneously shifted during the course of transportation development. This study aims to shed some light on how regulatory efforts from different government levels, taking into account their respective pros and cons, could be reconciled in a more effective governance structure that may provide an efficient, equitable, and sustainable transportation system from a long-term perspective.

\footnotetext{
${ }^{3}$ As Kirk (2004) demonstrated with highway statistics, Ohio has been a donee in six fiscal years during the period of 1981-2002, and a net donor for the other years.

${ }^{4}$ As Winston (2000) described, "transportation bills are loaded with demonstration or 'pork barrel' projects to ensure passage."
} 


\section{Governance choice from a fiscal federalism perspective}

To address the issue of how decision power could be allocated at different government levels, we must first take an in-depth look at a classic question in public economics: in a federation with two levels of (local vs. central) government, which level provides public goods more efficiently? ${ }^{5}$ At the heart of this problem is the tradeoff between the advantages and disadvantages of alternative regimes in providing public goods. Ignoring the issues of citizens' mobility across jurisdictions, ${ }^{6}$ local governments tend to provide public goods to a level that maximizes the aggregate surplus of their constituents, while neglecting benefits going to other districts. In the presence of positive spillovers across jurisdictions, ${ }^{7}$ local governments will tend to under-provide local public goods. In contrast, a central government may provide public goods more efficiently by internalizing the spillovers across local districts. The inefficiency of centralized decision making, though, is more controversial. The classic decentralization theorem developed by Oates (1972) describes centralized provision of public goods as a process by which a central government chooses a uniform level of public good for each district, stressing that a 'one size fits all' provision of public goods may fail to reflect local districts' differentiated preferences on public spending and thus undermine local interests. The modern literature, however, tends to eliminate the uniformity constraint because it is not realistic to assume a central government cannot differentiate the levels of spending in different districts. Centralized decision making may have other administrative disadvantages, such as additional overhead due to increased span of control and informational asymmetries associated with local needs. These factors, however, have not been formally modeled in literature.

In recent years, a rich literature of fiscal federalism has explicitly introduced political economy models to examine how conflicting local interests could result in suboptimal policy decisions in a legislature of locally elected representatives, which gives rise to another decentralizing force in the classic question of centralized versus decentralized provision of public goods. The conflicts essentially arise from distributive policy-making of a legislature that provides public goods whose benefits are geographically concentrated but costs generalized. It is expected that representatives will push for high spending favored by their jurisdiction but at the expense of other jurisdictions. ${ }^{8}$

In political science, legislative behavior has been modeled as cooperative or noncooperative from different perspectives, which divided the literature into two strands. ${ }^{9}$ The

\footnotetext{
${ }^{5} \mathrm{~A}$ broad literature of financial federalism has addressed this question, with a branch focusing on the discrete choice between centralized versus decentralized provision of general public goods. Epple and Nechyba (2004) has a thorough survey of this literature.

${ }^{6} \mathrm{~A}$ branch of literature, dating back to Tiebout (1956), sees the advantage of decentralization as stemming from the mobility of citizens across local jurisdictions and resultant decentralized policies more closely reflecting citizens' preferences. The advantage of decentralization associated with mobility, however, is not considered in this study.

${ }^{7}$ Positive spillovers exist when a public good provided in one district benefits the residents of other districts. Transportation infrastructure is a public good with positive spillovers. Ignoring tolls across jurisdictions, for example, outside travelers can use local roads without paying for them, which is referred to as the "free rider" phenomenon.

${ }^{8}$ Knight (2003), analyzing 1998 Congressional votes over transportation project funding, provided empirical evidence that legislators' probability of supporting a transportation project is increasing in own-district spending and decreasing in the tax burden associated with aggregate spending.

${ }^{9}$ The models of non-cooperative legislative processes originate from Buchanan and Tullock (1962); Riker (1962); while the early analytical work of cooperative legislative behavior dates back to Weingast (1979). Collie (1988) provides a survey of the two different approaches.
} 
cooperative view of legislative behavior assumes that representatives may exploit the benefits of universalistic cooperation in the legislature so that legislative policy decisions will maximize the benefits of all members. Nevertheless, Besley and Coate (2003) showed that suboptimal policy decisions may still result due to strategic delegation by jurisdictions in the cooperative legislature. From this standpoint, a series of legislative bargaining models has been developed to examine the inefficiency associated with strategic delegation in the cooperative legislature from different angles (Cheikbossian 2004; Redoano and Scharf 2004; Dur and Roelfsema 2005; Lorz and Willmann 2005). The cooperative view, however, neglects the difficulty in assembling and maintaining a universalistic coalition when members of Congress represent differing and competing demands, and when the number of representatives is large. Obviously both situations are not uncommon in multi-jurisdictional transportation systems. By contrast, a non-cooperative view of legislative behavior assumes that minimum winning coalitions of representatives will form when legislative decisions are taken by majority rule. The inefficiency of legislative decision-making, as Besley and Coate (2003) pointed out, thus arises from the uncertainty associated with the identity of the minimum winning coalition, and the misallocation of resources that takes place when a non-cooperative coalition makes legislative decisions.

The above economic models of the provision of general public goods, however, are limited when applied to transportation infrastructure. The limitation is twofold. First, the fiscal federalism literature in large part neglects where residents live and where they travel, therefore providing little insight into the role of spatial and demographic characteristics of geographically defined districts when investment decisions are made on a transportation infrastructure across the districts. For instance, the literature assumes a homogeneous spillover effect (defined as residents' preference for public spending in other districts over the spending in their own district) for simplicity. This assumption, though, is rarely true in the case of transportation infrastructure. Indeed, individuals' preferences for spending on transportation infrastructure in other districts vary by their residential location; so do their preferences for public spending on transportation over private consumption. ${ }^{10}$ Spatially differentiated spending preferences of individual residents may collectively play out in policy decisions through political processes. The fiscal federalism literature, however, has failed to capture the salient spatial dimension in the provision of transportation infrastructure. Furthermore, by assuming residents' spending preferences as exogenous, the existing literature lacks a dynamic view on the provision of transportation infrastructure. Unlike other public goods, such as schools and water treatment plants, spending on transportation infrastructure across districts changes the conditions on which the current spending decisions were made (by reducing transportation cost within and across districts and thus residents' preference for transportation spending), which will in turn affect the spending decisions in the subsequent period. Keeping in mind the mutual effects between spending decisions of local or central governments and spending preferences of individual residents, one would expect an evolving spending pattern in a sequential process of transportation infrastructure provision.

This study presents a spatio-economic analysis that re-addresses the question of which level (local or central) of government in a two-level federation may provide transportation infrastructure more efficiently, and examines the issue of why a centralizing tendency

\footnotetext{
${ }^{10}$ Intuitively, one can imagine that people who drive more on roads would prefer higher public road spending, and that people who travel more outside their home jurisdiction would prefer higher road spending in neighboring districts. Further, how much people travel and travel outside their residence district depends on how far away they live from the destinations of activities located within or outside the district.
} 
Fig. 2 Governance choice on two local districts

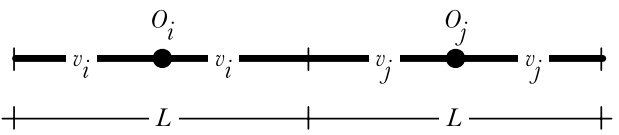

has been observed during the development of major transportation modes. While recognizing the benefits of centralization as improved coordination of interregional spillovers, this analysis introduces non-cooperative legislative decision processes in centralized provision of transportation infrastructure which may lead to inefficiency associated with uncertainty or misallocation. Local districts will weigh the benefits of alternative spending structures against their costs, and collectively decide in an autonomous political process which spending structure to adopt. This study also explores how the choice of centralized or decentralized spending structure might shift as transportation infrastructure improves and residents' preferences for spending change.

\section{Model setting}

To fix ideas, let us consider the following problem. Suppose that a one-dimensional space is divided into geographically defined districts indexed by $i=1, \ldots, n$. A continuum of residents lives on the space. Residents travel to reach their destinations where activities take place. It is assumed that activities are located only at the centers of districts. As illustrated in Fig. 2, jurisdictions (districts) build and share a joint road infrastructure throughout the space which serve residents' travel needs within and across districts. For simplicity, it is assumed that each district maintains a uniform level of service (operationalized by the average speed of vehicular travel on roads maintained by each jurisdiction $\left.v_{i}, i=1, \ldots, n\right)$ on the segment of road to its jurisdiction. Congestion is not dealt with in this analysis. Suppose that the districts initially maintain the same level of service on roads (indicated by $v_{0}$ ). In a decentralized spending structure, local governments or districts independently choose the level of road spending. In a centralized spending structure, on the other hand, a central government takes over the decision power and determines spending levels for all of the districts. While the analysis is generalizable to multiple jurisdictions, we further simplify the problem by adopting a familiar setup in the context of regional public good provision with two identical districts (indexed by $i, j$ ) to avoid redundant calculation and derive spending decisions in explicit forms. Districts have an equal size of $L$, represented by the distance between two boundary points of a jurisdiction. A summary of notation is given in Table 1.

Residents are characterized by the locations of their residence $x$ on the one-dimensional space ( $x$ indicates the relative position from the location of residence to the center of the residence district). The demand function $\rho(x, i)$ represents the number of trips that an individual resident living at $x$ makes to reach the activities located at the center of district $i$. Extending a double-cost approach, ${ }^{11}$ the utility of an individual resident takes the following form:

\footnotetext{
${ }^{11}$ An extended double-cost approach is adopted as a measure of performance in Buchanan and Tullock (1962) and Humplick and Moini-Araghi (1996). It accounts for two categories of costs: the first is resource costs, which are simply the costs of provision, administration, and management of roads. In this case, we consider only the costs of road improvement. And the second is preference costs, which are defined as costs incurred by road users, in this case the monetary cost of travel time that residents have spent on roads. In line with economic theory, the objective is set to minimize the total cost, which is the sum of preference costs and resource costs.
} 
Table 1 Notation

\begin{tabular}{|c|c|}
\hline Variable & Description \\
\hline$C, D$ & Centralization, decentralization \\
\hline$d$ & Distance \\
\hline$E$ & Road construction cost \\
\hline$f$ & Uniform tax \\
\hline$g, h$ & Derived functions \\
\hline$i, j$ & Indices of two neighboring districts \\
\hline$J$ & Jurisdiction \\
\hline$k$ & $\begin{array}{l}\text { Number of trips by an individual resident in a planning } \\
\text { period }\end{array}$ \\
\hline$L$ & The size of district \\
\hline$M$ & Median voter \\
\hline$n$ & Number of districts \\
\hline$p$ & Planning period \\
\hline$r$ & Residential density \\
\hline$t, T$ & Travel time of individual resident, jurisdiction \\
\hline$u, U$ & $\begin{array}{l}\text { Utility of individual resident, collective welfare of } \\
\text { jurisdiction }\end{array}$ \\
\hline$v_{0}$ & The initial road speed \\
\hline$v_{i}$ & Updated road speed chosen by district $i$ \\
\hline$x$ & Distance to the center of residence district \\
\hline$\alpha$ & Coefficients in the cost function \\
\hline$\beta$ & Weight central government puts on different districts \\
\hline$\delta$ & Multiplier in the demand function \\
\hline$\eta$ & Portion of trips going to the center of residence district \\
\hline$\lambda$ & Measure of spillover effects \\
\hline$\rho$ & Demand function \\
\hline$\tau$ & Value of time \\
\hline$\theta$ & The decay factor in the demand function \\
\hline
\end{tabular}

At a local level,

$$
u_{x}^{D}=-\tau t_{x}-f^{D}
$$

At a central level,

$$
u_{x}^{C}=-\tau t_{x}-f^{C}
$$

In either case, we assume that a uniform head tax will be charged on residents in order to finance road spending. Under decentralized spending we have:

$$
\int_{-L / 2}^{L / 2} r_{x} f^{D} d x \equiv E_{i}\left(v_{0}, v_{i}\right)
$$

Under the centralized spending structure, although spending decisions are made at a central level, it is assumed that road infrastructure is provided independently in different districts, so:

$$
\int_{-L / 2}^{L / 2} r_{x} f^{C} d x \equiv 1 / 2 \sum_{i} E_{i}\left(v_{0}, v_{i}\right)
$$


Fig. 3 An illustration of the endogenous choice of decision structure in a Pigouvian system of local governments

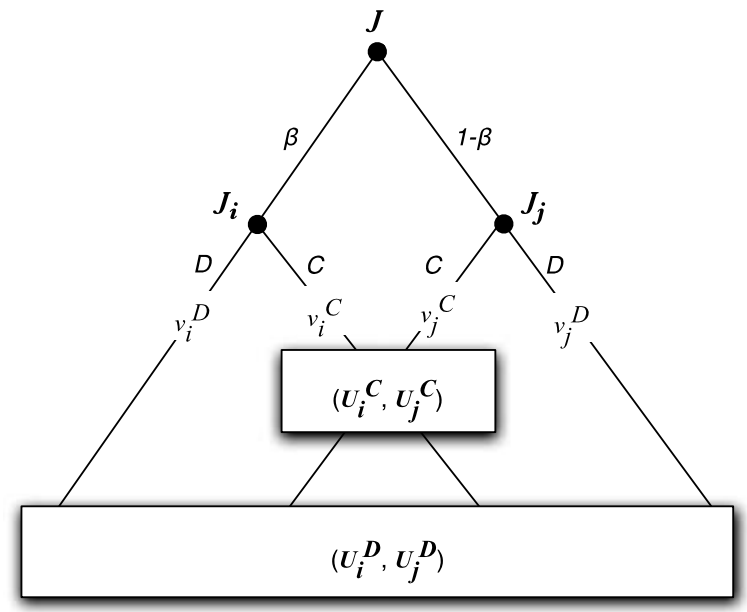

In aggregate, the welfare of residents in each district can be represented by:

$$
U_{i}^{D}=-\tau T_{i}-E_{i}\left(v_{0}, v_{i}\right)
$$

where

$$
T_{i}=\int_{-L / 2}^{L / 2} r_{x} t_{x} d x
$$

Ideally a central government aims to maximize the aggregate welfare of residents treating districts equally. Conflicting interests of local districts, however, may play out in the legislative decision-making processes and skew road spending across districts. This issue will be addressed later.

We envisage that spending decisions on roads result from the equilibrium of a two-stage political game played by jurisdictions. In the first stage, elected representatives of districts will make the choice of policy centralization or decentralization in a representative democracy. ${ }^{12}$ In a two-district context, a centralized structure is adopted if and only if both districts choose centralization. In the second stage, spending levels are determined at the center or in each district. If a centralized structure is adopted, a central government will take over the decision power and a legislature of locally elected representatives will determine the spending level in each district; if centralization is vetoed, each district will determine her spending level independently. Assuming a central government treats two member districts differently by putting different weights $\left(\beta_{i}\right)$ on the two districts (how the mistreatment could occur will be explained later), the game is illustrated in Fig. 3. As can be seen, two districts simultaneously decide which decision structure they would adopt (" $C$ " represents centralization, while " $D$ " represents decentralization); then spending decisions (speed levels) are made at either a central or local level.

\footnotetext{
${ }^{12}$ As Redoano and Scharf (2004) pointed out, there are two distinct political procedures for jurisdictions to determine whether or not to participate in policy coordination agreements. Under a direct democracy, citizens in each region decide whether or not to centralize by referendum; under a representative democracy, on the other hand, citizens delegate the decision to elected policy makers. This analysis considers only the latter system.
} 
Solving the game backwards, we first discuss spending decisions that will be made in a centralized versus decentralized structure. We then derive the collective choice of jurisdictions in terms of centralization versus decentralization by evaluating expected benefits and costs in alternative spending structures.

\section{Decisions on road spending}

From a normative standpoint, efficient spending decisions should maximize the total welfare of residents of interest. However, it is not realistic to expect the normative outcome will prevail when spending decisions are made politically. In this section, we start with a normative analysis which introduces a "Pigouvian" system of governments, ${ }^{13}$ which is followed by a Citizen-Candidate model in which political procedures are introduced to predict spending decisions at both a local and central level.

For the sake of simplicity, it is assumed that residents are uniformly distributed across space with a density of $r$. It is further assumed that each individual resident generates the same number of $k$ trips during a planning period, of which the same portion $(\eta)$ of trips goes to the center of the residence district. ${ }^{14}$ Defining the spillover effect as the ratio of total travel time one spends in the neighboring district to that in the residence district, the significance of spillovers can be measured as:

$$
\lambda_{x, i}= \begin{cases}2 k \eta \frac{-x}{v_{0}} /\left(2 k(1-\eta)\left(\frac{L / 2-x}{v_{0}}+\frac{L / 2}{v_{0}}\right)\right) & -L / 2 \leq x \leq 0 \\ 2 k \eta \frac{x}{v_{0}} /\left(2 k(1-\eta)\left(\frac{L / 2-x}{v_{0}}+\frac{L / 2}{v_{0}}\right)\right) & L / 2 \leq x \leq L\end{cases}
$$

Obviously the spillover effect varies by location, which distinguishes this spatioeconomic analysis from traditional discussions in fiscal federalism in the context of general public goods.

Following Newell (1980), the demand function decays with travel cost in a negative exponential form:

$$
\rho(x, i)=\delta e^{-\theta t(x, i)}
$$

Thus the portion of trips going to the residence district can be estimated as:

$$
\eta=\frac{\delta e^{-\theta \bar{t}(x, i)}}{\delta e^{-\theta \bar{t}(x, i)}+\delta e^{-\theta \bar{t}(x, j)}}=\frac{1}{1+e^{\theta \frac{\bar{d}(x, i)-\bar{d}(x, j)}{v_{0}}}}
$$

where $\bar{d}(x, i)$ and $\bar{d}(x, j)$ represent the average distance from a resident in district $i$ to the centers of district $i$ and district $j$, respectively. Under the assumption of uniform distribution

\footnotetext{
${ }^{13}$ In political economics, there are two extreme models of local government behavior: while the Leviathan rent maximizing model assumes an extremely selfish government which seeks to maximize its own revenue, in a Pigouvian model a government represents the interests of local residents and seeks to maximize the local welfare of its population. See Epple and Nechyba (2004) for a detailed explanation.

${ }^{14}$ The assumption of homogeneous travel demand on space, while to some extent simplifying reality, allows us to derive closed-form spending decisions analytically. Nevertheless, heterogeneity among residents is partially captured by their differentiated spatial locations of residence and accordingly varying travel distances to reach activities.
} 
of residents over space, it is easy to check that $\bar{d}(x, i)=L / 4$ and $\bar{d}(x, j)=3 L / 4$. Thus,

$$
\eta=\frac{1}{1+e^{-\frac{\theta L}{2 v_{0}}}}
$$

The above equation defines an inverse relationship between the in-district travel demand and the service level (speed) of the road infrastructure. When the speed is close to zero, indicating virtual isolation between the two districts, all trips are destined for the center of the home district $(\eta=1)$. When the speed increases to infinity, the two destinations are indifferent to any resident $(\eta=0.5)$. With an improving road speed during transportation development, we expect to see $\eta$ dropping from 1 to 0.5 .

In addition, we specify a Cobb-Douglas type of cost function on road investment as follows:

$$
E_{i}\left(v_{0}, v_{i}\right)=\alpha_{0} v_{0}^{\alpha_{1}}\left(v_{i}-v_{0}\right)^{\alpha_{2}} L^{\alpha_{3}} L
$$

Over small increments in road speed, it can be approximated as:

$$
E_{i}\left(v_{0}, v_{i}\right)=\alpha_{0} \alpha_{2} v_{0}^{\alpha_{1}}\left(v_{i}-v_{0}\right) L^{1+\alpha_{3}}
$$

With this, we finally have all the ingredients needed to derive the spending decisions made at a local or central level.

\subsection{Pigouvian governments model}

Under decentralized decision-making, benevolent local governments independently select the levels of road spending (represented by the improved road speed $v_{i}$ ) to maximize the total welfare of residents in the district:

$$
v_{i}^{D}=\underset{v_{i}}{\arg \max } U_{i}
$$

Under centralized decision-making, a central government selects the levels of road spending for each district to maximize the aggregate welfare of both districts while its preference for the districts is somehow skewed:

$$
v_{i}^{C}=\underset{v_{i}}{\arg \max } U^{C}
$$

If the central executive treats the benefit of each district equally, as Oates (1972) has already shown, centralized decision-making always will be superior to decentralized decisionmaking with the presence of positive interregional spillovers across districts and no diseconomies of scale. In reality, however, the central executive's spending decisions may be skewed as an outcome of political conflicts in legislative policy-making processes. ${ }^{15}$ Deferring the discussion of legislative behavior to the next section, this model assumes a central government aiming to maximize the aggregate welfare of districts while putting different weights on them:

$$
U^{C}=\sum_{i}\left(\beta_{i} U_{i}^{D}\right)
$$

\footnotetext{
${ }^{15}$ For instance, Cheikbossian (2004), assuming the central government is maximizing the weighted sum of the welfare of local regions, showed that the respective weight of each locality is determined by its lobbying efforts or rent-seeking expenditures.
} 
where

$$
\sum_{i} \beta_{i}=1
$$

Weights specified here $\left(\beta_{i}\right)$ can be viewed as exogenous and known to districts at this stage of the game, although they are endogenously determined when the spending structure is chosen, as explained in the next section too.

Following a step-by-step procedure in the Appendix, the Nash-equilibrium road spending strategies under local and central decision making were derived as follows:

$$
\begin{aligned}
& v_{i}^{D}=\sqrt{\frac{(1-\eta / 2) \tau r k L^{1-\alpha_{3}}}{\alpha_{0} v_{0}^{\alpha_{1}} \alpha_{2}}} \\
& v_{i}^{C}=\sqrt{\frac{\left(2-\left(2-\beta_{i}\right) \eta\right) \tau r k L^{1-\alpha_{3}}}{\alpha_{0} v_{0}^{\alpha_{1}} \alpha_{2}}}
\end{aligned}
$$

\subsection{Citizen-candidate model}

The Pigouvian Governments model does not explicitly consider the political forces that may influence road spending decisions at a local or central level. In a representative democracy, residents in each district can vote for representatives according to their spending preferences, and delegate their spending decision to the elected representatives; ${ }^{16}$ at a central level, a legislature constituted by locally elected representatives makes spending decisions for districts.

Under decentralized decision making, residents vote for the spending level in their residence district to maximize their individual utilities. The preference of an individual resident in district $i$ for the spending level in this district can be derived from:

$$
v_{x, i}^{D}=\underset{v_{i}}{\arg \max } u_{x}^{D}
$$

With majority rule and two competing political parties, it is suggested in the "median voter theorem" (Downs 1957) that the elected representative commits to a policy position preferred by the median-type voter. In this analysis, as spending preferences of individual residents vary by their residence locations, we need to find the location(s) $x_{i}^{M}$ where the median voter(s) live in order to predict the spending decision made by elected candidates.

Under centralized decision making, locally elected representatives form a legislature to determine road spending policies. From different perspectives, the legislature could be either cooperative or non-cooperative in nature. Extending Besley and Coate (2003), this analysis assumes a non-cooperative legislature in which representatives from each district form a coalition that commits to the same policy position. Each coalition could be thought of as a minimum winning coalition in the legislature while it is uncertain which coalition will be selected to determine spending policies. To simplify, it is assumed that each district elects one single representative that represents the minimum winning coalition of local representatives. In the case of two identical districts, it is further assumed that either representative has a chance to be selected as policy-maker in the legislature with equal probability.

\footnotetext{
${ }^{16}$ It is assumed in this analysis that all the residents have the right to vote as a citizen.
} 
When the representative from district $i$ is selected to determine the spending policy, the representative chooses spending levels for both districts preferred by the median voter in his home district:

$$
v_{i}^{C}=\underset{v_{i}}{\arg \max } u_{x, i}^{C}\left(x=x_{i}^{M}\right)
$$

Following the procedure described in the Appendix, we found that a median voter may live in either half of a district. The distance from the location of the median voter to the center of the district was derived as:

$$
\left\{\begin{array}{l}
x_{+}^{M}=\frac{1}{8 \eta} L \\
x_{-}^{M}=\frac{1-2 \eta}{8 \eta} L
\end{array}\right.
$$

Note that $x_{+}^{M}$ indicates the location of the median voter living closer to the neighboring district; while $x_{-}^{M}$ indicates the location farther from the neighboring district. Interestingly, the location of the median voter (and accordingly the local spending decision) depends on travel demand. As can be seen, when residents travel more frequently across the border (indicated by a smaller value of $\eta$ ), the median voter lives closer to the border.

Accordingly, the road spending level chosen through decentralized decision making is that preferred by the median voter:

$$
v_{i}^{D}=\sqrt{\frac{\left(1-\eta+\frac{2 \eta-1}{4 \eta}\right) \tau r k L^{1-\alpha_{3}}}{\alpha_{0} v_{0}^{\alpha_{1}} \alpha_{2}}}
$$

It is easy to check that:

$$
v_{i}^{D} \leq \sqrt{\frac{((1-\eta / 2)+(1 / 2-\sqrt{2} / 2)) \tau r_{i} k L^{1-\alpha_{3}}}{\alpha_{0} v_{0}^{\alpha_{1}} \alpha_{2}}}
$$

As compared to the local spending levels determined by Pigouvian local governments shown in (17), we can see that the election has led to suboptimal road spending at a local level due to competition between political parties.

Under centralized decision making, on the other hand, suppose that the minimum winning coalition from district $i$ wins the majority and takes over power in the legislature, then the representative from district $i$ chooses levels of spending for both home district and neighboring district as:

$$
\begin{aligned}
& v_{i}^{C}=\sqrt{\frac{2\left(1-\eta+\frac{2 \eta-1}{4 \eta}\right) \tau r k L^{1-\alpha_{3}}}{\alpha_{0} v_{0}^{\alpha_{1}} \alpha_{2}}} \\
& v_{j}^{C}=\sqrt{\frac{2(1-\eta) \tau r k L^{1-\alpha_{3}}}{\alpha_{0} v_{0}^{\alpha_{1}} \alpha_{2}}}
\end{aligned}
$$

\section{Choice of spending structure}

With predicted spending decisions at local and central levels, representatives of each district choose the spending structure favored by their home district by comparing the expected 
benefits associated with centralization versus decentralization, while the final choice is made collectively. In the case of two districts, the Nash-equilibrium condition under which a centralized structure is chosen can be translated as:

$$
U_{i}^{D} \leq U_{i}^{C} \quad \text { and } \quad U_{j}^{D} \leq U_{j}^{C}
$$

As shown in the Appendix, if it is assumed in the Pigouvian Governments model that the spending policies at a central level are skewed against district $i$ (i.e., $0 \leq \beta_{i} \leq 0.5$ ) without loss of generality, the equilibrium condition can be derived in a reduced form that reads:

$$
g\left(\eta, \beta_{i}\right) \leq 0,
$$

where the explicit form of $g\left(\eta, \beta_{i}\right)$ can be found in the Appendix.

It is worth noting that, the Ultimatum Game ${ }^{17}$ provides insight into how the value of $\beta_{i}$ could be endogenously determined when spending structure is chosen: the central government makes an offer (denoted by $\beta_{i}, 0 \leq \beta_{i} \leq 0.5$ ) to the disfavored local government (as the favored local government will always vote for centralization) and the local government can either accept this offer (by voting for centralization) or decline it (by voting against centralization). Empirical results suggest that a fair offer (a 50/50 split) will usually be made in a Ultimatum Game, ${ }^{18}$ while a unfair split that is less than $20 \%$ will always be declined (Henrich et al. 2004; Oosterbeek et al. 2004). Within this range the split may vary by the cultural and social nature of players. ${ }^{19}$

In the Citizen-Candidate model the equilibrium condition was derived as:

$$
h(\eta) \leq 0
$$

The explicit form of $h(\eta)$ can also be found in the Appendix.

The analysis has to this point focused on the choice of the spending structure in a static context with an exogenous road service level (represented by $v_{0}$ ). From an evolutionary perspective, the spending structure for a transportation system may shift as the infrastructure improves over time. When the system is in its birth phase, decentralization is favored as transportation cost is high and spillover effects are insignificant. When the infrastructure improves and travel costs are reduced, residents travel across borders at a higher frequency, leading to an increasing need to better address the issue of spillovers or free riders. When the need becomes prominent enough to overcome the inefficiency of centralization associated with legislative policy-making processes, districts will eventually switch to the centralized spending structure. This idea is illustrated numerically as follows.

In the Pigouvian Governments model, whether or not a centralized structure will be adopted, is determined by $g\left(\eta, \beta_{i}\right)$ where $0.5 \leq \eta \leq 1$ and $0 \leq \beta_{i} \leq 0.5$. We constructed

\footnotetext{
${ }^{17}$ First studied by Güth et al. (1982), the Ultimatum Game is a bargaining game in which two players decide how to divide a sum of money: while the first player proposes a division of the money, the second player decides whether to accept it. If accepted, players get their agreed upon shares; if rejected, both receive nothing.

${ }^{18}$ The Transportation Equity Act for the 21st Century (TEA-21), for example, provided a minimum guarantee program which ensures the return of highway funding to each state is no less than $90.5 \%$ of the state's tax payment to the Highway Trust Fund (Kirk 2004). This could be translated, in our case of two identical jurisdictions, into a Ultimatum offer of $50 \%$ with limited instability.

${ }^{19}$ Our model is different from the Ultimatum Game in that the disfavored local government will get more than nothing when rejecting the offer and going for decentralization. So the central government needs to make an even higher offer $\left(\beta_{i}\right)$ to reach an agreement than if in the Ultimatum Game.
} 


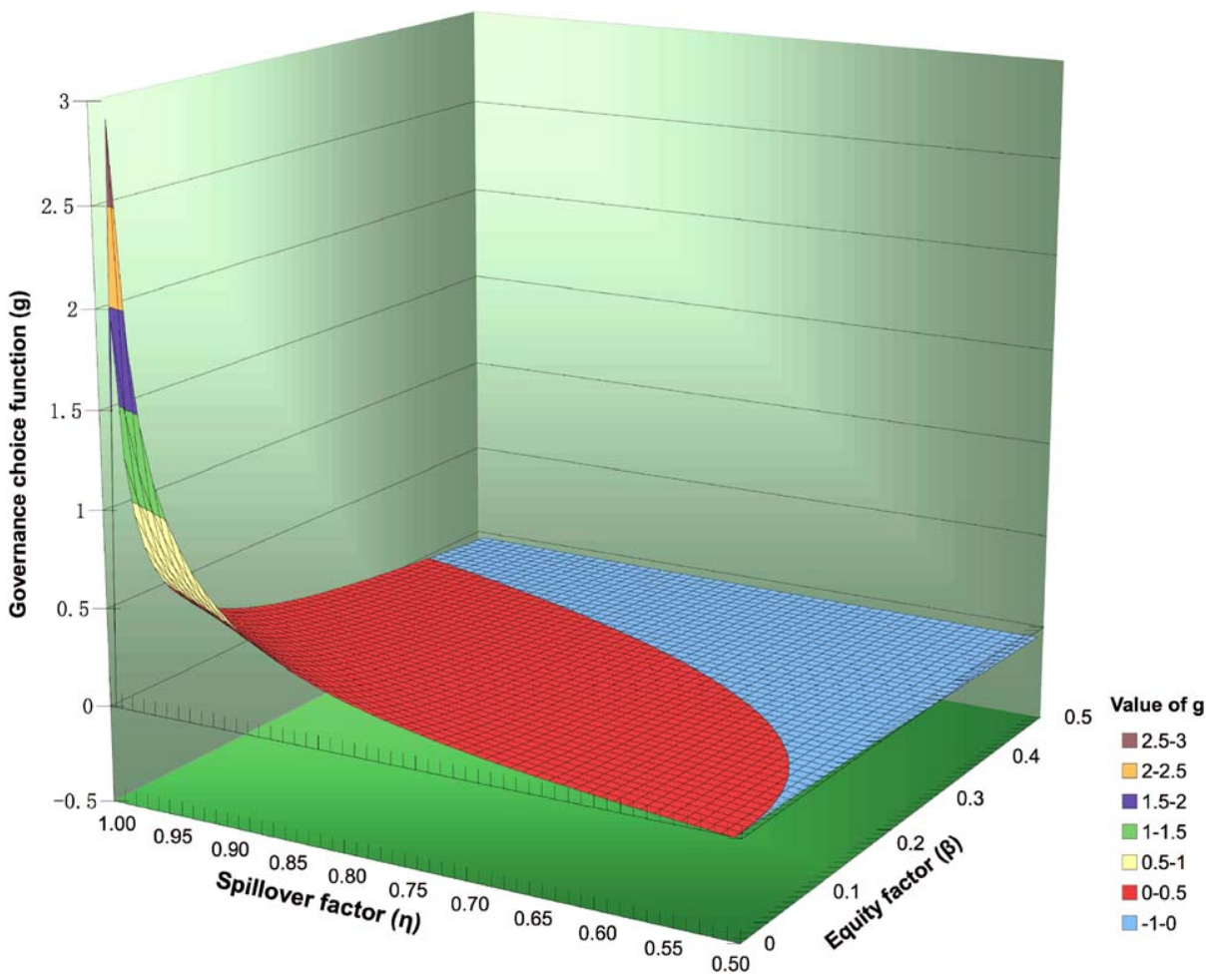

Fig. 4 A numeric illustration of the endogenous choice of decision structure with the change in $\eta$ and $\beta_{i}$ in the Pigouvian Governments model. A negative value of $g\left(\eta, \beta_{i}\right)$ indicates the adoption of a centralized structure

a numerical example to obtain perspective on the relationship between the choice of spending structure and the relative own-district demand $(\eta)$, as well as the central government's spending preference $\left(\beta_{i}\right)$. In doing so, we calculated $g\left(\eta, \beta_{i}\right)$ for each pair of $\eta(0.5 \leq \eta \leq 1)$ and $\beta\left(0 \leq \beta_{i} \leq 0.5\right)$ values with an interval of 0.01 . The change in $g\left(\eta, \beta_{i}\right)$ is plotted against $\beta_{i}$ and $\eta$ in Fig. 4. Note that centralization is adopted only if the governance choice function $g\left(\eta, \beta_{i}\right)$ has a negative value. Northeast corner of the graph, for instance, represents values of $g$ less than 0 , therefore favoring centralization. Note also that the equity factor $\beta$ represents the relative weight that the central government puts on the unfavorable local jurisdiction. A beta value closer to 0.5 indicates a more equitable treatment of local interests under centralization. The spillover factor $\eta$ denotes the portion of trips destined for the center of home district. A smaller $\eta$ indicates a more significant spillover effect, as more trips are crossing the border between districts. As can be seen in the graph, when $\beta=0.5$, meaning the central government treats two member districts equally, a centralized spending structure is always adopted as centralized decision making outperforms decentralization by internalizing the spillovers across jurisdictions. When $\beta_{i}=0$, on the other extreme, centralization is never adopted as the benefits of district $i$ would be completely ignored by the central executive. The reality, however, likely lies somewhere between the two extremes. When $0<\beta_{i}<0.5$, as can be seen, districts may prefer decentralization when the value of $\eta$ is large or the initial road speed $v_{0}$ is low (bear in mind that $\eta$ has an inverse relationship with $v_{0}$ ). As the road speed improves and value of $\eta$ drops, the districts may switch to cen- 


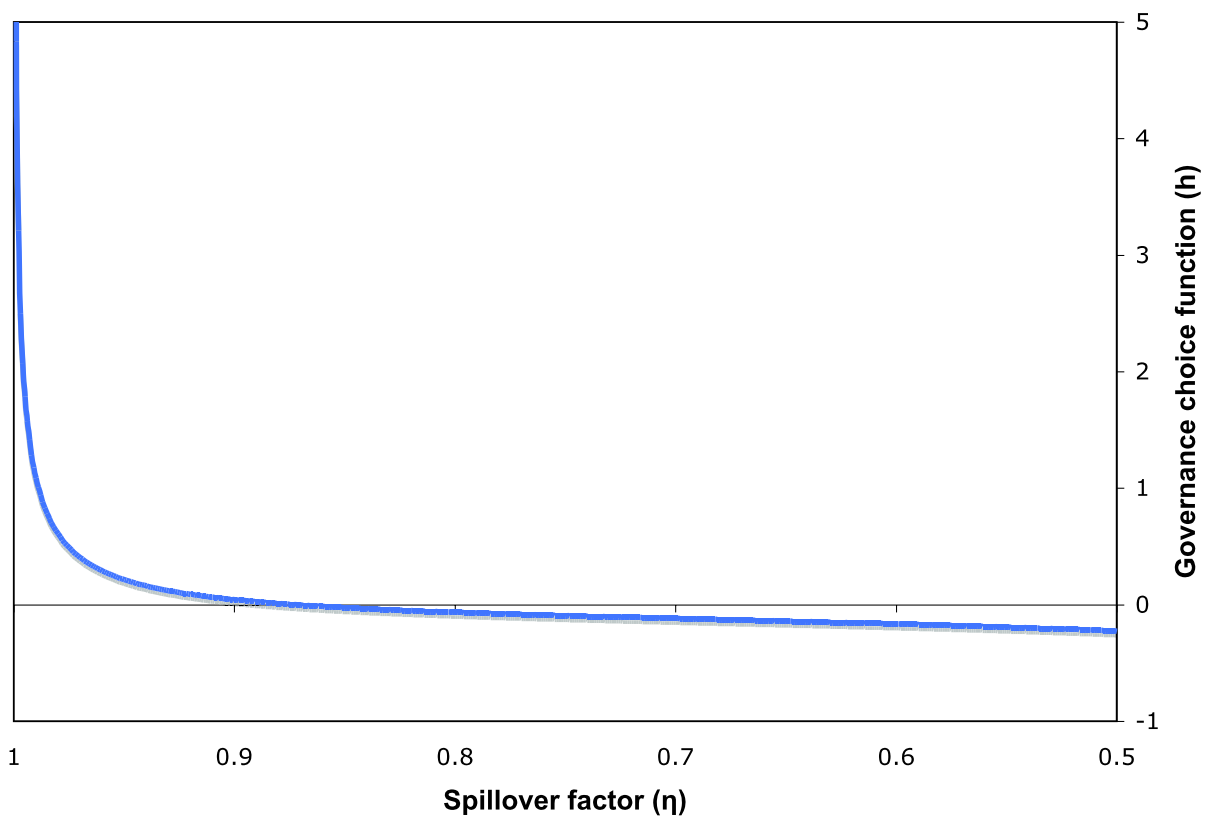

Fig. 5 A numeric illustration of the endogenous choice of decision structure with the change in $\eta$ in the Citizen-Candidate model. A negative value of $h(\eta)$ indicates policy centralization

tralization with an increasing need for coordination. The critical value of $\eta$ is larger with a higher value of $\beta_{i}$.

Similarly, the value of governance choice function $h(\eta)$ is calculated and plotted against $\eta$ in Fig. 5. As Fig. 5 displays, as $\eta$ decreases, the function changes from a positive value to a negative one, indicating that jurisdictions chose decentralization at the beginning, and then switched to centralization as the road infrastructure improves and travel demand across jurisdictions increases. A closer look at the numeric results discloses that the critical point of $\eta$ is around 0.872 .

\section{Endogenous shifts in governance choice}

Both the Pigouvian Governments model and Citizen-Candidate model demonstrate how governance choice could be made at a certain time point when road conditions and spillover effects are treated as exogenous. More interestingly, as we will illustrate later, the governance structure of a transportation system (in which the decision institution is chosen and spending decisions made) and service conditions on infrastructure are endogenous to each other in an evolutionary process of transportation development: as infrastructure improves after spending projects are implemented, people's traveling and spending preferences change accordingly, which, in turn, will find a way into the subsequent policy decisions through a collective political system. ${ }^{20}$ In reality, as transportation investment projects are

\footnotetext{
${ }^{20}$ Besides infrastructure conditions, many factors, such as population growth, technological advance, and induced demand, may influence spending decisions. Including these factors endogenously in our models, however, is beyond the scope of this analysis.
} 
Table 2 A numeric example of the coupled evolution of infrastructure and the governance structure in a sequential process

\begin{tabular}{lrlllll}
\hline$p$ & $r(p)$ & $v(p)$ & $\eta$ & $h(\eta)$ & Centralized & $v(p+1)$ \\
\hline 0 & 5,000 & 35.000 & 0.946 & 0.191 & No & 39.781 \\
1 & 5,750 & 39.781 & 0.925 & 0.106 & No & 40.366 \\
2 & 6,613 & 40.366 & 0.923 & 0.098 & No & 43.022 \\
3 & 7,604 & 43.022 & 0.911 & 0.067 & No & 44.923 \\
4 & 8,745 & 44.923 & 0.903 & 0.049 & No & 47.319 \\
5 & 10,057 & 47.319 & 0.892 & 0.030 & No & 49.668 \\
6 & 11,565 & 49.668 & 0.882 & 0.014 & No & 52.210 \\
7 & 13,300 & 52.210 & 0.872 & -0.0005 & Yes & N.A. \\
\hline
\end{tabular}

approved and delivered in discrete planning periods, we would envision incremental improvements to infrastructure coupled with gradual, sequential changes in policy decisions; when a critical point is reached, a spontaneous phase-shift of the spending structure will take place, as we have observed in various transportation systems. This process is demonstrated using a numeric example of the Citizen-Candidate model as follows.

Suppose that there are two local districts on a one-dimensional space with equal sizes $(L)$ of 20 kilometers and equal population of 100,000. Population is uniformly distributed over the space with a residential density $(r)$ of 5,000 persons per kilometer. We assume that an average person generates 10,000 trips $(k)$ from home in one planning period (say 10 years) and has a value of time $(\tau)$ of $\$ 10$ per hour. A road crosses both districts with an initial speed $\left(v_{0}\right)$ of 35 kilometers per hour. While fixing the travel demand $(k)$, we assume that the population in both districts is growing exogenously at a constant rate of 0.15 for each planning period. Finally, we arbitrarily specify the decline factor $\theta$ in the own-district demand function as 10.0, and the values of the cost function coefficients $\left(\alpha_{i}, i=0,1,2,3\right)$ as $1,000,1.25,1.25$, and 0.95 , respectively. It needs to be noted that while the specified values of the parameters capture some aspects of reality, they have not been calibrated with empirical data. They are used only for the demonstration of the idea.

Simulation results are displayed in Table 2. For each planning period $p$ the split of owndistrict demand $(\eta)$ is estimated according to the current population $(r(p))$ and road speed $(v(p))$. The function of $h(\eta)$ is then computed, and a centralized or decentralized spending structure is adopted according to its score. Finally, policy decisions are made in the chosen structure which, upon implementation, update the road speed for the next planning period $(v(p+1))$. As can be seen, in the beginning rounds the road service level (speed) is low and travel is mostly intra-district (with $\eta$ close to 1.0); a decentralized spending structure is always chosen under which local governments make incremental improvements to their own road segments. This lasts until the seventh consecutive planning period, when $\eta$ reaches the critical value of 0.872 , and the spending power is shifted to the central government, as the spillover effect becomes so prominent that the advantage of legislative decision making outweighs its inefficiency. Uncertainty subsequently arises regarding the updated road speeds under centralized control, depending on elected representatives from which district will win the majority and take over the decision power in the legislature.

\section{Findings and concluding remarks}

While transportation economists, public economists, and political scientists have examined governance choice in the provision of public goods from different perspectives, this research 
constructs a framework that accounts for the spatial, economic, and political dimensions of infrastructure provision in a holistic process. In particular, we analyze governance choice in a two-level federation in the provision of road infrastructure across geographically connected jurisdictions. It is demonstrated, on a serial road network shared by two districts, that residents' preferences for public spending on road infrastructure are differentiated by where they live and where they travel. A two-stage imperfect information game is then constructed to predict the choice of centralized or decentralized spending structure in a representative democracy, and the correspondent spending decisions at either a central or a local level.

This game is solved in two models that introduce different governmental decisionmaking processes. While the Pigouvian Governments model considers simple Pigouvian behavior of local and central governments, the Citizen-Candidate model explicitly introduces political procedures at both a local and central level as follows:

At a local level, residents in each district vote for representatives and delegate their spending decision to elected representatives. Under the assumption of two-party politics and majority rule, elected representatives will commit to a policy position preferred by the median voter. It is found that the location and preferred spending level of the median voter depends on in-district travel demand; it is also found that elected representatives, in order to win a majority in the election, tend to undersupply the infrastructure as compared to Pigouvian local governments.

At a central level, it is assumed that spending decisions are made in a legislature of locally elected representatives, where tradeoffs have to be made between the inefficiency of non-cooperative legislative policy making and its advantage in terms of better addressing spillovers across districts. It is shown in the two-district case that the inefficiency arises from the uncertainty of identifying the winning coalition in the legislature, and the misallocation of resources in favor of the home district of policy makers.

Both the Pigouvian Governments model and Citizen-Candidate model led to the finding that a centralized or decentralized spending structure is chosen based on a satisfactory compromise between benefits and costs associated with alternative decision-making processes at a certain time point, when road conditions and spillover effects are treated as exogenous. From an evolutionary perspective, on the other hand, governance patterns and service conditions on road infrastructure are endogenous to each other. It is demonstrated that governance choice could be treated as a function of changes in infrastructure, and that endogenous shifts in governance choice may take place when a tipping point of spillover effect is reached.

The goal of this study is to capture the essence of governance choice in a spatio-economic context. In order to derive spending decisions in explicit analytic forms, we sacrificed some realism by assuming a homogeneous travel demand over space and a non-cooperative legislature in this analysis. This could be improved by introducing more realistic travel demand forecasting and legislative decision-making processes.

The contributions of this study are several:

This research examines both individual and governmental decisions on road provision in a holistic framework. While individual transportation decisions are made based on the costs generated and the benefits received from their recurring travel needs, governance choice and governmental spending decisions are derived as a collective function of spatially differentiated spending preferences of individuals in a democratic referendum system. Although it has focused on the symmetric case with two identical districts, this analysis is generalizable to examine multiple jurisdictions in an asymmetric situation, for which results may differ significantly. From a nominal perspective, this framework could be extended to evaluate the 
efficiency and equity associated with infrastructure provision at alternative institutional levels, and examine how conflicting interests and regulatory efforts could be reconciled in a mixed governance structure.

Our models are also useful to address contemporary transportation issues with governmental involvement, such as project selection, congestion pricing, and "cap-and-trade." Take the transit line ("the Purple Line") being proposed to connect Prince George's County and Montgomery County of Maryland as an example (Maryland Transit Administration 2009). Controversies over whether this line is going to be built as a train or an express bus line involve a dimension of economic, spatial, and political considerations, such as the distinct construction costs associated with alternative proposals, the uneven distribution of job opportunities and travel needs across the two counties, and the uncertain splits of funding sources from federal, state, and local governments. Our models provide a framework in which these factors could be accounted for in an integrated political-economic process, which existing models in public economics, transportation, and political science have to treat separately. With empirical data available, extensions to our models could find applications in explaining what actually happened or are happening in the real-world infrastructure provision processes.

From an evolutionary perspective, this analysis points out governance structure is not static in the infrastructure provision processes. The numerical simulation illustrates the idea that as transportation infrastructure improves after incremental investments and technological advance, the desired choice of governance may spontaneously switch from decentralization to centralization when an endogenous tipping point of a shift is reached. This finding corroborates the historical observation that the development of major transportation systems in the United States was usually accompanied with a centralizing tendency of decision power, and provides implications for policy issues, such as regulation, decentralization, privatization, and road pricing from an innovative perspective of the coupled evolution of infrastructure and institutional decision-making. Even in the absence of empirical data, this research makes significant theoretical advances over the formal models yet devised in the literature that have no way of accounting for these endogenous changes in governance structure.

\section{Appendix}

\subsection{Pigouvian governments model}

On a one-dimensional space, it is easy to check the travel times that an individual resident living at $x$ needs to reach the centers of each district:

To reach the center of residence district,

$$
t(x, i)= \begin{cases}\frac{-x}{v_{i}} & -L / 2 \leq x \leq 0 \\ \frac{x}{v_{i}} & L / 2 \leq x \leq L\end{cases}
$$

To reach the center of neighboring district,

$$
t(x, j)=\frac{L / 2-x}{v_{i}}+\frac{L / 2}{v_{j}}
$$

With the assumption of fixed demand, the total travel time an individual resident living at $x$ spends on roads for a planning period can be calculated as: 


$$
\begin{aligned}
t_{x} & =\sum_{i}(2 \rho(x, i) t(x, i)) \\
& = \begin{cases}2 k \eta \frac{-x}{v_{i}}+2 k(1-\eta)\left(\frac{L / 2-x}{v_{i}}+\frac{L / 2}{v_{j}}\right) & -L / 2 \leq x \leq 0 \\
2 k \eta \frac{x}{v_{i}}+2 k(1-\eta)\left(\frac{L / 2-x}{v_{i}}+\frac{L / 2}{v_{j}}\right) & L / 2 \leq x \leq L\end{cases}
\end{aligned}
$$

Assuming a uniform distribution of residents across space, we obtained the total travel time residents in district $i$ spend on roads in the district by integrating individual travel time across a district:

$$
\begin{aligned}
T_{i}= & \int_{-L / 2}^{L / 2} r_{x} t_{x} d x \\
= & \int_{-L / 2}^{0}\left\{2 r k \eta \frac{-x}{v_{i}}+2 r k(1-\eta)\left(\frac{L / 2-x}{v_{i}}+\frac{L / 2}{v_{j}}\right)\right\} d x \\
& +\int_{0}^{L / 2}\left\{2 r k \eta \frac{x}{v_{i}}+2 r k(1-\eta)\left(\frac{L / 2-x}{v_{i}}+\frac{L / 2}{v_{j}}\right)\right\} d x \\
= & \frac{(1-\eta / 2) r k L^{2}}{v_{i}}+\frac{(1-\eta) r k L^{2}}{v_{j}}
\end{aligned}
$$

A benevolent local government considers both resources cost (road spending) and user cost (travel time cost) during decision making of road speed:

$$
\begin{aligned}
U_{i}^{D} & =-C_{i}\left(v_{0}, v_{i}\right)-\tau T_{i} \\
& =-\tau \alpha_{0} v_{0}^{\alpha_{1}} \alpha_{2}\left(v_{i}-v_{0}\right) L^{1+\alpha_{3}}-\frac{(1-\eta / 2) r k L^{2}}{v_{i}}-\frac{(1-\eta) r k L^{2}}{v_{j}}
\end{aligned}
$$

The road speed chosen by a local government is obtained by taking the first derivative of its utility function with respect to the road speed in this district,

$$
\begin{aligned}
& \frac{\partial U_{i}^{D}}{\partial v_{i}^{D}}=0 \\
& \Rightarrow \quad-\frac{(1-\eta / 2) r k L^{2}}{\left(v_{i}^{D}\right)^{2}}+\tau \alpha_{0} v_{0}^{\alpha_{1}} \alpha_{2} L^{1+\alpha_{3}}=0 \\
& \Rightarrow \quad v_{i}^{D}=\sqrt{\frac{(1-\eta / 2) r k L^{1-\alpha_{3}}}{\tau \alpha_{0} v_{0}^{\alpha_{1}} \alpha_{2}}}
\end{aligned}
$$

Under centralized decision making, it is assumed that the central government aims to maximize the aggregate surplus of both districts while putting different weights on them,

$$
\begin{aligned}
U^{C}= & \beta_{i} U_{i}^{C}+\beta_{j} U_{j}^{C} \\
= & -\beta_{i}\left\{\frac{(1-\eta / 2) r k L^{2}}{v_{i}}+\frac{(1-\eta) r k L^{2}}{v_{j}}+\tau \alpha_{0} v_{0}^{\alpha_{1}} \alpha_{2} \frac{\left(v_{i}-v_{0}+v_{j}-v_{0}\right)}{2} L^{1+\alpha_{3}}\right\} \\
& -\left(1-\beta_{i}\right)\left\{\frac{(1-\eta / 2) r k L^{2}}{v_{j}}+\frac{(1-\eta) r k L^{2}}{v_{i}}+\tau \alpha_{0} v_{0}^{\alpha_{1}} \alpha_{2} \frac{\left(v_{i}-v_{0}+v_{j}-v_{0}\right)}{2} L^{1+\alpha_{3}}\right\}
\end{aligned}
$$


Road speeds chosen for two districts can be obtained by taking the first derivative of the central government's utility function with respect to the road speed in the two districts, respectively:

$$
\begin{aligned}
& \frac{\partial U^{C}}{\partial v_{i}^{C}}=0 \\
& \Rightarrow \quad-\frac{\beta_{i}(1-\eta / 2) r k L^{2}}{\left(v_{i}^{C}\right)^{2}}+\frac{1}{2} \tau \alpha_{0} v_{0}^{\alpha_{1}} \alpha_{2} L^{1+\alpha_{3}}-\frac{\left(1-\beta_{i}\right)(1-\eta) r k L^{2}}{\left(v_{i}^{C}\right)^{2}}=0 \\
& \Rightarrow \quad v_{i}^{C}=\sqrt{\frac{\left(2-\left(2-\beta_{i}\right) \eta\right) r k L^{1-\alpha_{3}}}{\tau \alpha_{0} v_{0}^{\alpha_{1}} \alpha_{2}}}
\end{aligned}
$$

Without loss of generality, it is assumed that the spending policies at a central level is skewed against district $i$ (i.e., $0 \leq \beta_{i} \leq 0.5$ ). District $j$ will benefit from the misallocation at the expense of district $i$. Therefore, if district $i$ votes for centralization, district $j$ will always vote for centralization. In this case, the adoption of a centralized structure depends on the following requirement:

$$
\begin{gathered}
U_{i}^{D}<=U_{i}^{C} \\
\Leftrightarrow \quad-U_{i}^{C}<=-U_{i}^{D} \\
\Leftrightarrow \quad \frac{(1-\eta / 2) r k L^{2}}{v_{i}^{C}}+\tau \alpha_{0} v_{0}^{\alpha_{1}} \alpha_{2} \frac{v_{i}^{C}+v_{j}^{C}-2 v_{0}}{2} L^{1+\alpha_{3}}+\frac{(1-\eta) r k L^{2}}{v_{j}^{C}} \\
\quad \leq \frac{(1-\eta / 2) r k L^{2}}{v_{i}^{D}}+\frac{(1-\eta) r k L^{2}}{v_{j}^{D}}+\tau \alpha_{0} v_{0}^{\alpha_{1}} \alpha_{2}\left(v_{i}^{D}-v_{0}\right) L^{1+\alpha_{3}} \\
\Leftrightarrow \quad g\left(\eta, \beta_{i}\right)=\left(1-\frac{\eta}{2}\right)\left(\sqrt{\frac{2-\left(2-\beta_{i}\right) \eta}{4(1-\eta / 2)}}+\sqrt{\frac{2-\left(1+\beta_{i}\right) \eta}{4(1-\eta / 2)}}+\sqrt{\frac{1-\eta / 2}{2-\left(2-\beta_{i}\right) \eta}}-2\right) \\
\quad-(1-\eta)\left(1-\sqrt{\frac{1-\eta / 2}{2-\left(1+\beta_{i}\right) \eta}}\right) \leq 0
\end{gathered}
$$

\subsection{Citizen-candidate model}

According to the assumption that uniform taxes are charged to finance road provision under either centralized or decentralized decision making, the taxes that a resident needs to pay can be calculated as:

Under decentralized decision making,

$$
f^{D}=\frac{\alpha_{0} \alpha_{2} v_{0}^{\alpha_{1}}\left(v_{i}-v_{0}\right) L^{1+\alpha_{3}}}{r L}
$$

Under centralized decision making,

$$
f^{C}=\frac{\alpha_{0} \alpha_{2} v_{0}^{\alpha_{1}}\left(v_{i}+v_{j}-2 v_{0}\right) L^{1+\alpha_{3}}}{2 r L}
$$


Under decentralized decision making, residents vote for a road speed that maximizes their individual utility. The utility function of a resident takes the following form:

$$
\begin{aligned}
u_{x, i}^{D} & =-\tau t_{x}-f^{D} \\
& = \begin{cases}-2 k \tau\left(-\eta \frac{1}{v_{i}}+(1-\eta) \frac{\frac{L}{2}-x}{v_{i}}+(1-\eta) \frac{\frac{L}{2}}{v_{j}}\right)-\frac{1}{r} \alpha_{0} \alpha_{2} v_{0}^{\alpha_{1}}\left(v_{i}-v_{0}\right) L^{\alpha_{3}} & -L / 2 \leq x \leq 0 \\
-2 k \tau\left(\eta \frac{1}{v_{i}}+(1-\eta) \frac{\frac{L}{2}-x}{v_{i}}+(1-\eta) \frac{\frac{L}{2}}{v_{j}}\right)-\frac{1}{r} \alpha_{0} \alpha_{2} v_{0}^{\alpha_{1}}\left(v_{i}-v_{0}\right) L^{\alpha_{3}} & L / 2 \leq x \leq L\end{cases}
\end{aligned}
$$

The favored speed of an individual resident can thus be derived by taking the first derivative of his/her utility function with respect to the road speed in the residence district:

$$
v_{x, i}^{D}= \begin{cases}\sqrt{\frac{\left(1-\eta-\frac{2 x}{L}\right) \tau r k L^{1-\alpha_{3}}}{\alpha_{0} v_{0}^{\alpha_{1}} \alpha_{2}}} & -L / 2 \leq x \leq 0 \\ \sqrt{\frac{\left(1-\eta+\frac{2 x}{L}(2 \eta-1)\right) \tau r k L^{1-\alpha_{3}}}{\alpha_{0} v_{0}^{\alpha} \alpha_{2}}} & L / 2 \leq x \leq L\end{cases}
$$

Note that whether a resident lives to the left or right of the district center, the preferred road speed increases monotonically with the distance from residential location to the center. Suppose that residents living at $x_{-}$on the half farther from the border between two districts and at $x_{+}$on the half closer to the border prefer the same level of road spending. It is easy to check that:

$$
\frac{-2 x_{-}}{L}=\frac{2 x_{+}}{L}(2 \eta-1)
$$

In order to become a median voter, the median voter theorem suggests that there should be half of the voters who prefer a road speed that is lower than the median-type road speed. Based on the assumption of uniform distribution of residents across space, a median voter lives in a location that satisfies:

$$
\frac{x_{-}}{-\frac{L}{2}}+\frac{x_{+}}{\frac{L}{2}}=\frac{1}{2}
$$

Solving the above two equations jointly, we obtain the locations where median voters live:

$$
\left\{\begin{array}{l}
x_{+}^{M}=\frac{1}{8 \eta} L \\
x_{-}^{M}=\frac{1-2 \eta}{8 \eta} L
\end{array}\right.
$$

Accordingly, the elected representative commits a road speed preferred by median voters as:

$$
v_{i}^{D}=\sqrt{\frac{\left(1-\eta+\frac{2 \eta-1}{4 \eta}\right) \tau r k L^{1-\alpha_{3}}}{\alpha_{0} v_{0}^{\alpha_{1}} \alpha_{2}}}
$$

Under centralized decision making, it is assumed that representatives elected from districts will form minimum winning coalitions in the legislature. Each coalition has equal possibility to attract majority of the legislature.

Suppose that the representative from district $i$ is selected to determine road spending policy. It is assumed that the representative aims to choose spending levels for both districts 
while aiming to maximize the utility of the median voter in home district, which can be translated into:

$$
\begin{aligned}
u_{x_{-}^{M}, i}^{C} & =-\tau t_{x}-f^{C} \\
& =-\tau\left(2 k \eta \frac{-x_{-}^{M}}{v_{i}}+2 k(1-\eta)\left(\frac{L / 2-x_{-}^{M}}{v_{i}}+\frac{L / 2}{v_{j}}\right)\right)-\frac{\alpha_{0} \alpha_{2} v_{0}^{\alpha_{1}}\left(v_{i}+v_{j}-v_{0}\right) L^{1+\alpha_{3}}}{2 r L} \\
& =-2 k \tau\left(-\eta \frac{1}{v_{i}}+(1-\eta) \frac{L / 2-x_{-}^{M}}{v_{i}}+(1-\eta) \frac{L / 2}{v_{j}}\right)-\frac{1}{2 r} \alpha_{0} \alpha_{2} v_{0}^{\alpha_{1}}\left(v_{i}+v_{j}-v_{0}\right) L^{\alpha_{3}}
\end{aligned}
$$

In this case, it is easy to derive the levels of road spending for both districts:

$$
\left\{\begin{array}{l}
v_{i}^{C}=\sqrt{\frac{2\left(1-\eta+\frac{2 \eta-1}{4 \eta}\right) \tau r k L^{1-\alpha_{3}}}{\alpha_{0} v_{0}^{\alpha_{1}} \alpha_{2}}} \\
v_{j}^{C}=\sqrt{\frac{2(1-\eta) \tau r k L^{1-\alpha_{3}}}{\alpha_{0} v_{0}^{\alpha} \alpha_{2}}}
\end{array}\right.
$$

Thus, the aggregate welfare in district $i$ can be calculated as:

$$
U_{i}^{C}=-\frac{1}{2}\left(\frac{(1-\eta / 2) \tau r k L^{2}}{v_{i}^{C}}+\alpha_{0} v_{0}^{\alpha_{1}} \alpha_{2}\left(\frac{v_{i}^{C}+v_{j}^{C}}{2}-v_{0}\right) L^{1+\alpha_{3}}+\frac{(1-\eta) \tau r k L^{2}}{v_{j}^{C}}\right)
$$

Similarly, if the representative from district $j$ wins the majority, the levels of road spending for both districts can be derived as:

$$
U_{i}^{C}=-\frac{1}{2}\left(\frac{(1-\eta / 2) \tau r k L^{2}}{v_{j}^{C}}+\alpha_{0} v_{0}^{\alpha_{1}} \alpha_{2}\left(\frac{v_{i}^{C}+v_{j}^{C}}{2}-v_{0}\right) L^{1+\alpha_{3}}+\frac{(1-\eta) \tau r k L^{2}}{v_{i}^{C}}\right)
$$

As can be seen in either case, the policy maker tends to oversupply the road infrastructure in his/her home district, and undersupply that in the neighboring district.

There is equal probability for the representative from district $i$ and that from district $j$ to take the decision power in the legislature. Thus the expected utility function of an elected representative from district $i$ can be formulated as:

$$
\begin{aligned}
U_{i}^{C}= & -\frac{1}{2}\left(\frac{(1-\eta / 2) \tau r k L^{2}}{v_{i}^{C}}+\alpha_{0} v_{0}^{\alpha_{1}} \alpha_{2}\left(\frac{v_{i}^{C}+v_{j}^{C}}{2}-v_{0}\right) L^{1+\alpha_{3}}+\frac{(1-\eta) \tau r k L^{2}}{v_{j}^{C}}\right) \\
& -\frac{1}{2}\left(\frac{(1-\eta / 2) \tau r k L^{2}}{v_{j}^{C}}+\alpha_{0} v_{0}^{\alpha_{1}} \alpha_{2}\left(\frac{v_{i}^{C}+v_{j}^{C}}{2}-v_{0}\right) L^{1+\alpha_{3}}+\frac{(1-\eta) \tau r k L^{2}}{v_{i}^{C}}\right)
\end{aligned}
$$

Policy centralization is adopted when both districts vote for centralization, thus the condition on which centralization is chosen can be derived as:

$$
\begin{aligned}
U_{i}^{D}<= & U_{i}^{C} \\
& \Leftrightarrow \quad-U_{i}^{C}<=-U_{i}^{D} \\
& \Leftrightarrow \quad \frac{1}{2}\left(\frac{(1-\eta / 2) \tau r k L^{2}}{v_{i}^{C}}+\alpha_{0} v_{0}^{\alpha_{1}} \alpha_{2}\left(\frac{v_{i}^{C}+v_{j}^{C}}{2}-v_{0}\right) L^{1+\alpha_{3}}+\frac{(1-\eta) \tau r k L^{2}}{v_{j}^{C}}\right)
\end{aligned}
$$




$$
\begin{aligned}
& +\frac{1}{2}\left(\frac{(1-\eta / 2) \tau r k L^{2}}{v_{j}^{C}}+\alpha_{0} v_{0}^{\alpha_{1}} \alpha_{2}\left(\frac{v_{i}^{C}+v_{j}^{C}}{2}-v_{0}\right) L^{1+\alpha_{3}}+\frac{(1-\eta) \tau r k L^{2}}{v_{i}^{C}}\right) \\
& \leq \frac{(1-\eta / 2) \tau r k L^{2}}{v_{i}^{D}}+\frac{(1-\eta) \tau r k L^{2}}{v_{i}^{D}}+\alpha_{0} v_{0}^{\alpha_{1}} \alpha_{2}\left(v_{i}^{D}-v_{0}\right) L^{1+\alpha_{3}} \\
& \Leftrightarrow h(\eta)=\frac{(\sqrt{2} / 2-2)(1-3 \eta / 4)}{\sqrt{1-\eta+\frac{2 \eta-1}{4 \eta}}}+(\sqrt{2} / 2-1) \sqrt{1-\eta+\frac{2 \eta-1}{4 \eta}}+\frac{2-7 \eta / 4}{\sqrt{2(1-\eta)}} \\
& <=0
\end{aligned}
$$

\section{References}

Besley, T., \& Coate, S. (2003). Central versus local provision of public goods: a political economy analysis. Journal of Public Economics, 87(4), 2611-2637.

Bogart, D. (2005). Turnpike trusts, infrastructure investment, and the road transportation revolution in eighteenth-century England. The Journal of Economic History, 65, 540-543.

Borger, B. D., Proost, S., \& Dender, K. V. (2005). Congestion and tax competition in a parallel network. European Economic Review, 2013-2040.

Buchanan, J., \& Tullock, G. (1962). The calculus of consent, logical foundations of constitutional democracy. Ann Arbor: The University of Michigan Press.

Button, K. (1998). Infrastructure investment, endogenous growth and economic convergence. Annals of Regional Science, 32, 145-162.

Cheikbossian, G. (2004). Lobbying and rent-seeking for public goods in a fiscally centralized system. Annales D Economie Et De Statistique, 331-351.

Collie, M. (1988). The legislature and distributive policy making in formal perspective. Legislative Studies Quarterly, 13, 427-458.

de Palma, A., \& Lindsey, R. (2000). Private toll roads: competition under various ownership regimes. Annals of Regional Science, 34, 13-35.

Downs, A. (1957). An economic theory of democracy. New York: Harper and Row.

Dur, R., \& Roelfsema, H. (2005). Why does centralisation fail to internalise policy externalities? Public Choice, 122, 395-416.

Epple, D., \& Nechyba, T. (2004). Fiscal decentralization. In V. Henderson \& J. Thisse (Eds.), Handbook of regional and urban economics (Vol. 4, pp. 2423-2480). Amsterdam: North-Holland/Elsevier.

Federal Highway Administration (2002). Highway Statistics 2002. http://www.fhwa.dot.gov/policy/ohim/ hs02/hf.htm.

Garrison, W., \& Levinson, D. (2005). The transportation experience: policy, planning, and deployment. London: Oxford University Press.

Güth, W., Schmittberger, R., \& Schwarze, B. (1982). An experimental analysis of ultimatum bargaining. Journal of Economic Behavior and Organization, 3(4), 367-388.

Haynes, K. E., Gifford, J. L., \& Pelletiere, D. (2005). Sustainable transportation institutions and regional evolution: global and local perspectives. Journal of Transport Geography, 13, 207-221.

Henrich, J., Boyd, R., Bowles, S., Camerer, C., Fehr, E., \& Gintis, H. (2004). Foundations of human sociality: economic experiments and ethnographic evidence from fifteen small-scale societies. London: Oxford University Press.

Humplick, F., \& Moini-Araghi, A. (1996). Is there an optimal structure for decentralized provision of roads? Policy Research Working Paper 1657. World Bank, Policy Research Department, Washington, DC.

Johnson, R., \& Libecap, G. (2000). Political processes and the common pool problem: the federal highway trust fund. Working Paper, Department of Economics. Tucson, AZ: University of Arizona.

Kirk, R. S. (2004). Federal-aid highway program: “donor-donee” state issues, CRS (Report for Congress). Order Code RL31735.

Knight, B. (2003). Parochial interests and the centralized provision of local public goods: evidence from congressional voting on transportation projects. Working Paper No. W9748, National Bureau of Economic Research. 
Levinson, D. (2002). Financing transportation networks, Edward Elgar Publishing.

Levinson, D., \& Yerra, B. (2002). Highway costs and the efficient mix of state and local funds. Transportation Research Record, 1812, 27-36.

Lorz, O., \& Willmann, G. (2005). On the endogenous allocation of decision powers in federal structures. Journal of Urban Economics, 57, 242-257.

Maryland Transit Administration (2009). The purple line's official website. http://www.purplelinemd.com/ overview.

McDaniel, W., \& Coley, M. (2004). History of the highway trust fund. Transportation Research Record, $1885,8-14$.

Newell, G. F. (1980). Traffic flow on transportation networks. Cambridge: MIT Press.

Oates, W. E. (1972). Fiscal federalism. New York: Harcourt Brace Jovanovich.

Oosterbeek, H., Sloof, R., \& van de Kuilen, G. (2004). Differences in ultimatum game experiments: evidence from a meta-analysis. Experimental Economics, 7, 171-188.

Redoano, M., \& Scharf, K. A. (2004). The political economy of policy centralization: direct versus representative democracy. Journal of Public Economics, 88, 799-817.

Riker, W. (1962). The theory of political coalitions. New Haven: Yale University Press.

Taaffe, E., Gauthier, H., \& O’Kelly, M. (1996). Geography of transportation.

Taylor, B. (2004). The geography of urban transportation finance. In S. Hanson \& G. Giuliano (Eds.), The geography of urban transportation. New York: The Guilford Press.

Tiebout, C. (1956). A pure theory of local expenditures. Journal of Political Economy, 64(5), 416-424.

Verhoef, E. T., \& Rouwendal, J. (2004). Pricing, capacity choice, and financing in transportation networks. Journal of Regional Science, 44, 405-435.

Verhoef, E. T., Nijkamp, P., \& Rietveld, P. (1996). Second-best congestion pricing: the case of an untolled alternative. Journal of Urban Economics, 40, 279-302.

Weingast, B. (1979). A rational choice perspective on congressional norms. American Journal of Political Science, 23, 245-262.

Winston, C. (2000). Government failure in urban transportation. Fiscal Studies, 21(4), 403-425.

Zhang, L., \& Levinson, D. (2007). The economics of transportation network growth. In P. C. Millán \& V. Inglada (Eds.), Essays on transportation economics. Berlin: Springer. 